\title{
Secondary cardiac tumor
}

\section{Alma Sijamija**, CNermir Granov², (1)Omer Perva ${ }^{2}$ (1) Nedžad Hadžić}

'Travnik General Hospital, Travnik, Bosnia and Herzegovina

${ }^{2}$ Clinical Center University of Sarajevo, Sarajevo, Bosnia and Herzegovina
RECEIVED:

October 28, 2018

ACCEPTED:

November 5, 2018

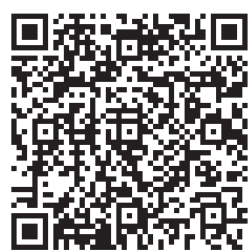

KEYWORDS: cardiac tumor, metastasis.

CITATION: Cardiol Croat. 2018;13(11-12):415. | https://doi.org/10.15836/ccar2018.415

*ADDRESS FOR CORRESPONDENCE: Alma Sijamija, Travnik General Hospital, Department of Internal Diseases, Kalibunar bb, Travnik, Bosnia and Herzegovina. / Phone: +387-61-780-085 / E-mail: alma.sijamija@hotmail.com ORCID: Alma Sijamija, http://orcid.org/0000-0003-2818-0501 • Nermir Granov, http://orcid.org/0000-0002-6228-6230 Omer Perva, http://orcid.org/0000-0003-2645-1558 • Nedžad Hadžić, http://orcid.org/0000-0002-7186-7803

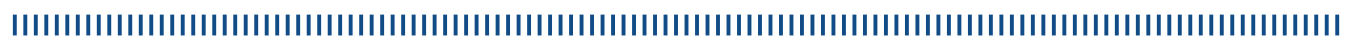

Background: Cardiac secondaries of peripheral tumors can occur by means of hematogenous or lymphogenous spread. With an incidence of up to $1 \%$ at necropsy, metastatic deposits to the heart are more than 20 times more common than are primary tumours. ${ }^{1-3}$ There are several clinical features, that are seen commonly with cardiac tumors: embolization, obstruction, arrhythmias. Metastases to the heart are, clinically silent in $90 \%$ of cases. Echocardiography is the first diagnostic procedure Owing to the small numbers of cases there is no evidential basis for the optimal treatment regime.

Case report: 49-year-old patient was admitted to our department due to dyspnea, palpitation, hemodynamic instability. 12 lead ECG: supraventricular tachycardia208 bpm, right bundle branch block. Medical history: hysterectomy with adnexectomy 5 years ago, due to sarcoma of uterus with high degree of malignancy. Completed treatment of chemotherapy and radiotherapy. Laboratory results: elevated tumor marker Ca 125: $366 \mathrm{U} / \mathrm{ml}$ and D dimmer 7.46 ug/ml, others found neat. Echocardiography: the enlargement of right heart cavities dimensions, along the entire free wall of the right ventricle (RV) visible tumor mass that starts from the free wall and affects more than $2 / 3$ of the volume of RV, fills the RV outflow tract and is partly seen in the pulmonary artery and the mobile formation $21 \times 23 \mathrm{~mm}$ passes through the tricuspid valve and pendulates between right atrium and RV causing an almost severe tricuspid stenosis - with TV PGmax of 4.5mmHg. After introducing into the sinus rhythm, the patient was hemodynamically stable for 30 days, until a new episode of disease progression occurred. X-ray and CT scan of the lung s confirm the enlarged shadow of the heart. The lower right pulmonary lobe consists of the secondary deposit mutually with smaller pleural effusions. Abdominal CT: ascites, enlarged aorto-caval lymph nodes. Ca 125 increasing: $2092 \mathrm{U} / \mathrm{ml}$. Two months after the onset of cardiorespiratory symptoms Superior vena cava syndrome started to dominate. In consultation with a cardiac surgeon, oncologist, gynecologist, because of the aggressiveness of the tumor process, we have decided to conduct palliative medical care.

Conclusion: The development of cardiorespiratory symptoms in a patient with carcinoma should raise the suspicion of cardiac metastases. Surgical management is generally critical, as the metastases are often neither solitary nor confined to the heart.

LITERATURE IIIIIIIIIIIIIIIIIIIIIIIIIIIIIIIIIIIIIIIIIIIIIIIIIIIIIIIIIIIIIIIIIIIIIIIIIIIIIIIIIIIIIIIIIIIIIIIIIIIIIIIIII

1. Bussani R, De-Giorgio F, Abbate A, Silvestri F. Cardiac metastases. J Clin Pathol. 2007 Jan;60(1):27-34. https://doi.org/10.1136/jcp.2005.035105

2. Lam KY, Dickens P, Chan AC.Tumors of the heart. A 20-year experience with a review of 12,485 consecutive autopsies. Arch Pathol Lab Med. 1993 Oct:117(10):1027-31. PubMed: https://www.ncbi.nlm.nih.gov/pubmed/8215825

3. Abraham KP, Reddy V, Gattuso P. Neoplasms metastatic to the heart: review of 3314 consecutive autopsies. Am J Cardiovasc Pathol. 1990;3(3):195-8. PubMed PMID: 2095826. PubMed: https://www.ncbi.nlm.nih.gov/pubmed/2095826 